DOSSIÊ TEMÁTICO: Política de Educação Superior

do] https://doi.org/10.22481/praxisedu.v16i41.7256

\title{
DA AUTONOMIA À HETERONOMIA UNIVERSITÁRIA: DIRETRIZES PARA UM NOVO ORDENAMENTO DA EDUCAÇÃO SUPERIOR
}

\author{
FROM AUTONOMY TO UNIVERSITY HETERONOMY: GUIDELINES FOR A NEW \\ ORDINATION OF HIGHER EDUCATION
}

\author{
DE LA AUTONOMÍA A LA HETERONOMÍA UNIVERSITARIA: DIRECTRICES PARA \\ UNA NUEVA ORDENACIÓN DE LA EDUCACIÓN SUPERIOR
}

\author{
Iracema Oliveira Lima \\ Universidade Estadual do Sudoeste da Bahia - Brasil \\ Leila Pio Mororó \\ Universidade Estadual do Sudoeste da Bahia - Brasil
}

\begin{abstract}
Resumo: A partir de uma revisão bibliográfica e documental, este artigo defende a autonomia universitária como um princípio necessário e inquebrantável, principalmente no atual contexto nacional no qual o papel do ensino superior vem sendo questionado e as instituições universitárias atacadas por grupos obscurantistas que assumiram, em 2019, os cargos de gestão pública. Para tanto, resgata o significado adquirido por esse princípio nas legislações brasileiras ao longo do século $\mathrm{XX}$, localizandoo sócio, político e economicamente, procurando demonstrar como, a partir do final desse século e nas primeiras décadas do século XXI, a heteronomia passa a ser parte constitutiva da realidade da educação superior brasileira, produzindo a sua subserviência ao capital.
\end{abstract}

Palavras chave: Ensino Superior; Autonomia Universitária; História da organização da educação superior brasileira.

\begin{abstract}
Based on a bibliographic and documentary review, this article defends university autonomy as a necessary and unbreakable principle, especially in the current Brazilian national context in which the role of higher education has been questioned and university institutions attacked by obscurantist groups that have assumed, in 2019, public management positions. To this end, it rescues the meaning acquired by this principle in Brazilian legislation throughout the 20th century, locating it socially, politically and economically, seeking to demonstrate how, from the end of that century and in the first decades of the 21 st century, heteronomy becomes to be a constitutive part of the reality of Brazilian higher education, producing its subservience to capital.
\end{abstract}

Keywords: Higher Education; University Autonomy; History of the organization of Brazilian higher education. 
Resumen: Basado en una revisión bibliográfica y documental, este artículo defiende la autonomía universitaria como un principio necesario e irrompible, especialmente en el contexto nacional brasileño actual en el que el papel de la educación superior ha sido cuestionado y las instituciones universitarias atacadas por grupos oscurantistas que han asumido, en 2019, puestos de gestión pública. Con este fin, rescata el significado adquirido por este principio en la legislación brasileña a lo largo del siglo XX, ubicándolo social, política y económicamente, buscando demostrar cómo, desde el final de ese siglo y en las primeras décadas del siglo XXI, la heteronomía se convierte en ser parte constitutiva de la realidad de la educación superior brasileña, produciendo su sumisión al capital.

Palabras clave: Educación superior; Autonomía universitária; Historia de la organización de la educación superior brasileña.

\section{Introdução}

A discussão a respeito da autonomia universitária como um princípio necessário, inquebrantável e, ao mesmo tempo, resistente na sociedade brasileira, é retomada em um contexto nacional no qual o papel da universidade vem sendo questionado e suas instituições cruelmente atacadas por grupos obscurantistas que assumiram em 2019 no Brasil cargos de gestão pública. Como exemplo dessa situação, é possível registrar a fala do Ministro da Educação, Abraham Weintraub, o qual, orquestrando a implementação do FUTURE-SE, projeto que ataca as universidades e institutos federais de educação, afirmou em sessão $1^{\text {a }}$ Sessão Legislativa Ordinária da 56 ${ }^{\mathrm{a}}$ Legislatura $104^{\mathrm{a}}$ Sessão (sessão deliberativa ordinária), em 15 de maio de 2019 que, "autonomia universitária não é soberania. As universidades têm que respeitar as leis. E se preciso for, a polícia tem que entrar, sim, na universidade". Na perspectiva do Ministro, a lei deve ser a máxima ordenadora da sociedade, desde que, evidentemente, ela esteja alinhada com os interesses dos que ocupam posições de decisões políticas no momento.

Procuramos assim, neste momento, discutir o significado da autonomia como condição ímpar da instituição universitária, ao tempo em que se faz o resgate do significado que esse princípio foi adquirindo nas legislações brasileiras ao longo do século $\mathrm{XX}$, e, na medida do possível, localizá-la sócio-político e economicamente, até o atual contexto do século XXI, quando analisamos o aparato jurídico institucional orquestrado para mitigar as conquistas anteriormente alcançadas.

Reiteradas vezes, críticas são dirigidas à forma como ocorreu a discussão sobre a autonomia universitária, especialmente nos momentos em que duas leis gerais relacionadas à educação superior brasileira - que estiveram maior tempo em vigor - foram promulgadas. A primeira foi o Estatuto das Universidades Brasileiras, promulgada em 1931, no governo 
provisório de Getúlio Vargas, tendo à frente o jurista Francisco Campos, o qual estabeleceu parâmetros para as organizações administrativa e pedagógica da universidade brasileira em conformidade com a estrutura organizacional que a Universidade do Rio de Janeiro possuía à época. A segunda lei, a Reforma da Educação Superior de 1968, a qual, ao tempo que disciplinou a educação superior durante o regime civil militar também propiciou a abertura para a expansão da educação superior privada, impondo severos custos político-institucionais à autonomia universitária. Aprovadas em períodos tão controversos da história política do país, essas leis, ao utilizarem o termo "autonomia universitária", o fizeram por aproximação aos modelos de administração e gerenciamento dos setores privados de organização do trabalho, demonstrando que a lógica da expressão, desde seus primórdios legais, genuinamente esteve vinculada aos interesses do capital.

A aproximação do conceito de autonomia universitária, sempre atrelado aos interesses do capital, independentemente do contexto histórico e das reformas educacionais, pode até se demonstrar diferente quando à forma, mas mantém-se inalterada quanto à suas finalidades. Segundo Mészaros, (2008, p. 27, grifos originais), os reformistas, em contexto capitalista, mesmos os mais bem intencionados, poderiam, no limite "apenas utilizar as reformas educacionais que propusessem para remediar os piores efeitos de ordem reprodutiva capitalista estabelecida sem, contudo, eliminar os seus fundamentos causais antagônicos e profundamente enraizados."

Assim sendo, dialogando com o referido autor, concordamos que não há outra forma de buscar uma alternativa diferente para a autonomia universitária se não houver uma ruptura com a lógica do próprio capital, pois os impactos dessa lógica sobre a universidade brasileira já podem ser considerados incorrigíveis.

Neste texto serão abordadas, por meio da história da organização da educação superior brasileira, as primeiras discussões relacionadas ao princípio pétreo ${ }^{1}$ da autonomia universitária e sua relação intrínseca com a lógica do capital. Na sua primeira sessão, contextualizaremos a aprovação da Lei de Reforma do Ensino Superior. Posteriormente, a partir das discussões relacionadas a reestruturação do Estado, orquestrada especialmente a partir da década de1990, reafirmando a tutela que o Estado impõe às Instituições de Educação Superior - IES, serão apresentados os contextos da promulgação da Constituição Federal de 1988 e da Lei de

1 Muitas vezes, no caso brasileiro, o princípio pétreo é lido como "pátrio", ou mesmo não lido, vez que sua existência frequentemente é interpretada como anomia ou mesmo heteronomia. 
Diretrizes e Bases da Educação Nacional de 1996 - Lei 9.394/96. Em ambas sessões, será anunciado como se deu o debate sobre a autonomia universitária e os embates ideológicos que atravessavam as discussões.

Por fim, pontuamos como que estas legislações pavimentaram as condições ideais para que a autonomia universitária fosse, nesse percurso, sendo substituída pela heteronomia, que tem como marca a subserviência das universidades às regras impostas por órgãos e editais que atuam em esferas outras que não na estrutura jurídico-institucional das universidades públicas brasileiras.

\section{Marcas da fragilidade da Autonomia Universitária nos anos de Ditadura Civil Militar}

Os anos que antecederam ao golpe civil-militar foram marcados por conflitos de interesses econômicos e políticos resultantes do esgotamento do modelo de substituição de importações de bens de consumo. Os movimentos sociais intensificam a sua crítica ao governo e procuram ampliar sua participação/representação na política nacional. A disputa estabelecida entre os que defendiam a internacionalização da economia brasileira e os que defendiam o projeto nacionalista, a exemplo do Partido Social Democrata (PSD) e do Partido Trabalhista Brasileiro (PTB), é contemporânea ao cenário que marcou a proliferação de golpes militares. Tais golpes assolaram alguns países da América do Sul, a exemplo do Brasil em 1964, onde procederam na imposição do governo ditatorial à sociedade brasileira, resultante da associação da burguesia nacional/internacional e os militares.

$\mathrm{Na}$ década de 1960, tanto a história política quanto a educacional presenciaram avalanches de legislações que ordenaram a nova estrutura político-educacional brasileira. Para Saviani (1987), a Lei de Diretrizes e Bases da Educação Nacional - Lei nº 4.024/61, aprovada pelo Congresso Nacional, representou o consenso entre o projeto original - elaborado no período do então Ministro da Educação Clemente Mariani, entre os anos de 1947/48 - e o substitutivo proposto por Carlos Lacerda, revelando, mais uma vez, a conciliação entre as concepções de educação e os interesses em disputas naquele palco político. Anísio Teixeira, no Diário de Pernambuco, expressou sua opinião acerca do texto aprovado: "Meia vitória, mas vitória"; já Álvaro Vieira Pinto assim entendia: "É uma lei com a qual ou sem a qual, tudo continua tal e qual", ao tempo em que Carlos Lacerda entendia que a 4.024/61 foi a lei possível na época. 
Também organizada em maio de 1961, a União Nacional dos Estudantes - $\mathrm{UNE}^{2}$ realizou, na Bahia, o Primeiro Seminário Nacional da Reforma Universitária com as seguintes questões: a) representação dos docentes e dos discentes na administração universitária, por meio de critério da proporcionalidade; b) autonomia universitária; c) instituição do regime de trabalho em tempo integral para a carreira docente; d) ampliação da oferta de vagas nas escolas públicas; e) flexibilidade na organização de currículos.

Nesse Seminário, o movimento estudantil sistematizou sua posição crítica com relação à estrutura universitária vigente e delineou um projeto de reforma. Ou seja, apresentou algumas reflexões sobre as bases de uma Reforma Universitária. As conclusões desse Seminário foram divulgadas à sociedade por meio do documento intitulado Carta da Bahia ${ }^{3}$. Seu texto revelava a posição do movimento estudantil em combater o caráter obsoleto e elitista das instituições universitárias brasileiras com críticas ao arcaísmo, à falta de autonomia, ao que denominava "ditadura dos professores". Desta forma, reivindicou a democratização da instituição, ao tempo que propunha uma maior aproximação entre a universidade e a sociedade por meio de projetos de extensão, mediante a oferta de cursos à parcela da sociedade que não tivera acesso à educação superior.

Com esse documento os estudantes ratificaram a importância da preservação da autonomia universitária nas questões pedagógicas e acadêmico-administrativas, pontuando a premência da dedicação exclusiva dos docentes para o pleno desenvolvimento do trabalho acadêmico. Denunciavam os vícios que o regime de cátedras ${ }^{4}$ impunham ao funcionamento autônomo das universidades, ao tempo em que propunham como forma de democratização do espaço universitário a participação proporcional por categoria nos órgãos da administração acadêmica.

Impulsionados também por essas críticas, os reitores envidavam esforços junto ao então Ministro da Educação, Antônio de Oliveira Brito, para realizar um simpósio entre os dirigentes das universidades, com o objetivo de discutir a urgência de uma reforma universitária. Segundo

2 Naquela época, a UNE já havia alcançado prestígios políticos em função dos trabalhos de conscientização e mobilização dos estudantes organizados desde o início do século XX, especialmente em função das reflexões então acumuladas a partir da Reforma de Córdoba na Argentina, que se tornara referência na América Latina.

3 Conforme prática dos movimentos organizados por associações, os documentos síntese de um determinado evento recebiam o nome da cidade, região onde foram realizadas as discussões da temática proposta. Como sugestão para leitura e aprofundamento sugere-se Fávero (1994).

4 As cátedras ou cadeiras de disciplinas foram instituídas por D. João VI aqui no Brasil e representavam o maior nível que um professor poderia ocupar na docência na educação superior. Sobre este tema sugerimos a leitura do texto de Fávero (2000). 
Cunha (1983), neste mesmo período, o Ministro da Educação, preocupado com as críticas dirigidas à educação superior e pela divulgação da Carta da Bahia, reúne-se com o Diretor da Divisão de Ensino Superior/MEC, com a representação da UNE, da União dos Estudantes Secundaristas - UES e do Diretório Central dos Estudantes - DCE, na tentativa de minimizar as manifestações e a insatisfação dos estudantes.

Em reuniões específicas, os dirigentes das universidades também expressaram preocupações relacionadas, principalmente, à necessidade de ampliação da oferta de vagas, entendendo, assim, essa ampliação como um imperativo não só para o processo de democratização, como também para os desenvolvimentos social e econômico do país. Para Cunha, a aplicabilidade da ampliação de vagas deveria resultar de um planejamento de cada unidade universitária, com o devido acompanhamento e fiscalização do Ministério da Educação - MEC. Quanto às medidas de longo alcance, essas seriam realizadas por meio da Reforma Universitária. No entendimento de Cunha, a realização daquele simpósio resultou em três propostas principais, que seriam:

[...] a integração das universidades e das escolas superiores isoladas em sistemas; a manutenção, senão ampliação da autonomia dessas instituições diante do MEC; a cooptação dos estudantes na implementação da reforma do ensino superior, sob a direção da burocracia educacional. (CUNHA, 1983, p. 248)

Para implementar essas propostas, foram instituídas a Comissão Nacional da Reforma Universitária, pelo MEC, e as Comissões Secionais, pelas universidades - todas trabalhariam na elaboração da reforma universitária. A Comissão Nacional, presidida pelo próprio Ministro da Educação, foi composta, por indicação deste, de "pessoas de irrecusável autoridade no campo do ensino superior e representativas das grandes correntes do pensamento educacional brasileiro" (CUNHA, 1983, p. 201), do Fórum Universitário, constituído por todos os reitores das universidades brasileiras, e por representantes da UNE. Segundo Cardoso (1989), com estes expedientes, o governo reforçava as tradições centralizadora e autoritária do Estado Brasileiro, em criar comissões de alto nível, de legislar pelo alto, sem instituir o debate.

Em função das divergências relacionadas ao planejamento e à estruturação da Reforma Universitária, tanto por parte dos estudantes quanto dos reitores, essa comissão acabou por dissolver-se. Naquela composição, somente o Fórum Universitário, criado em 1962, e o Conselho Federal de Educação (CFE), instalado por meio da Portaria $n^{\circ}$ 67, de 27 de fevereiro de 1962, deram continuidade aos trabalhos propostos. 
Diante da urgência de serem adotadas medidas que objetivassem as modificações na educação superior, o CFE realizou uma avaliação dos estatutos das universidades, tentando, quando possível, adequá-los ao que estava estabelecido na LDB (Lei no 4.024/61) e, desta forma, conduzir o processo construtivo da reforma universitária. Poucos meses depois da sua organização, este Conselho passou a publicar na revista Documenta, seu órgão oficial, notas contendo informações sobre o início da reforma universitária ${ }^{5}$, levando ao conhecimento público as medidas tomadas. Segundo Cunha (1983), o CFE, utilizando-se da sua prerrogativa de acompanhar e normatizar o funcionamento da educação nacional, emitiu tantas normas que, após cinco anos, fazia-se necessário um aparato jurídico para consolidar todas as suas deliberações ${ }^{6}$.

Diante desse quadro, a inclusão da discussão sobre essa reforma na pauta governamental tornara-se inevitável. No entanto, não apenas em função da necessidade de abrandar os ânimos universitários que, mesmo com a UNE na ilegalidade desde 1964, continuavam transformando o espaço da universidade no locus ideal para as contestações política e social ${ }^{7}$, mas também, ou especialmente, em função da necessidade que o governo identificava de modernizar a estrutura universitária a fim de torná-la contemporânea às demandas apontadas pelas novas ordens econômico-social e política, ou seja, direcioná-las aos interesses do capital.

Com o golpe militar em 1964, as diretrizes político-econômicas foram redirecionadas. O governo ditatorial, apoiado desde o princípio pela burguesia nacional e pelo capital estrangeiro, suspende o diálogo com o movimento estudantil e com os diversos setores da sociedade civil organizada. A pauta política é suspensa, as reformas de base deixam de ser discutidas e um novo direcionamento político-econômico é tramado. O modelo a ser executado pode ser chamado de técnico-burocrático-capitalista dependente (CUNHA, 1983).

O movimento pró-expansão e modernização da universidade brasileira, bandeira do movimento estudantil já há algum tempo, tem um novo desdobramento. Agora as motivações estavam alicerçadas na propulsão do desenvolvimentismo controlado; e a racionalização, a eficiência e a produtividade tornam-se valores absolutos a serem perseguidos e alcançados.

5 Nas "Notas" publicadas na revista Documenta n³, maio 1962, p.8 e nº, setembro 1962, p.8, escritas por Celso Kelly, o CFE defendia que "mais que uma reforma, uma revolução universitária" estava sendo processada no ensino superior.

6 No ano de 1998, Valdemar Sguissardi e Marília Morosini, publicaram no UNIVERSITAS-BR a coletânea que aborda desde a Reforma Universitária de 1968 até os anos de 1998: A Educação Superior em Periódicos Nacionais, em que Niuvenius Paoli apresenta o perfil da revista Documenta.

7 A promulgação da Lei $\mathrm{n}^{\circ} 4.464 / 64$ decretou o fechamento da UNE, que, somente a partir de 1985, por meio da promulgação da Lei $n^{\circ} 7.395 / 85$, voltou, legalmente, a participar das questões que envolviam a educação superior. 
Neste processo, a educação recebeu uma atenção especial por parte do governo militar que, alicerçando-se nos discursos da modernização e expansão, começou a traçar as primeiras metas de reestruturação da educação superior brasileira. Essa seria a vertente que propiciaria ao país acelerar o seu desenvolvimento produtivo-tecnológico. Segundo Florestan Fernandes (1979), a iniciativa do governo em realizar a Reforma Universitária, propalada há tempos pelo movimento estudantil, justifica-se quando consideramos que:

[...] sob a pressão constante de tendências modernizadoras que partiam do interior do País, dos Estados Unidos e de organismos econômicos, educacionais e culturais internacionais, e sob o desafio crescente da rebelião estudantil, a reação conservadora preferiu tomar a liderança política da "reforma universitária". Iria, portanto, modernizar sem romper com as antigas tradições, nem ferir interesses conservadores. Ao mesmo tempo iria controlar a inovação. (FERNANDES, 1979, p. 58)

Saviani (1987) assevera que na vigência do governo ditatorial, fortalecido pela condição imposta ao Congresso Nacional, fisiologicamente limitado a homologar as decisões do Executivo, foram introduzidas modificações na organização educacional que revelavam a ruptura política processada no ano de 1964. Em 1968, também à revelia das discussões acumuladas pelos diversos segmentos da sociedade civil e sob a chancela de um grupo de especialistas, foi promulgada a Lei da Reforma Universitária - Lei 5.540/68 ${ }^{8}$. Assim, mais uma vez, foi elaborada uma legislação pelo alto, fruto do autoritarismo, resultante das contradições que o cerceamento à oposição poderia significar. Segundo representantes da sociedade civil, naquela oportunidade, "tivemos a reforma universitária possível " que passava bastante distante dos anseios da comunidade universitária.

Embora a autonomia universitária estivesse assegurada na condição de princípio, verifica-se que essa, ao mesmo tempo, estava submetida aos interesses dominantes, ou seja, foi pensada e legitimada tendo em vista o projeto político do período. A situação política atípica gerava também contradições, pois ao tempo em que firmava a educação superior como instrumento propulsor da autonomia nacional - investindo para isso na qualificação stricto sensu do quadro docente, em instalações físicas e em equipamentos de laboratórios -, também estabelecia mecanismos legais para manter sob sua tutela a comunidade acadêmica. Enfim,

8 Objetivando reformular e modernizar a educação superior brasileira aos moldes do projeto de desenvolvimento arquitetado pelos militares, foi promulgada a Lei $\mathrm{n}^{\circ}$. 5.540/68, revelando o caráter dicotômico do período. No artigo $3^{\circ}$, ficou estabelecido que "as universidades gozarão de autonomia didático-científica, disciplinar, administrativa e financeira, que será exercida na forma da lei e de seus estatutos". Embora, estivesse presente nas principais reformas educacionais do País, a autonomia universitária não se apresentava como uma realidade no interior das instituições universitárias. 
pode-se considerar que parte das reformas no campo da educação superior procurou adequá-la às mudanças sociais, políticas e econômicas estabelecidas e vigentes num determinado momento histórico.

Ainda no ano de 1967, foram firmados acordos técnicos e financeiros entre o Ministério da Educação e Cultura (MEC) e a Agência Norte-Americana para o Desenvolvimento Internacional (USAID), que se tornou a principal interlocutora junto ao Conselho Federal de Educação nas questões relacionadas à reforma universitária. Embora a presença desta agência norte-americana no Brasil date de meados dos anos de 1950, somente a partir daquele período é que passou a exercer um papel mais marcante na política nacional.

Esta agência lançou duras críticas à forma de organização da educação superior brasileira, com exceção ao Instituto Tecnológico de Aeronáutica - ITA e a Universidade de Brasília - UnB. Segundo suas orientações, competiam a este nível de formação a qualificação de mão de obra voltada para as demandas apresentadas pelo mercado de trabalho. Assim, os cursos de licenciaturas seriam estruturados conforme o modelo americano dos teachers colleges - estabelecimentos dedicados à formação do professor, que conjugava educação superior científico e profissional. Propunha, ainda, a flexibilização do conceito de universidade, ao sugerir a criação de estabelecimentos similares aos community colleges, ou seja, cursos de nível superior com menor duração e voltados exclusivamente ao mercado de trabalho.

Neste processo, a Diretoria do Ensino Superior do MEC convida Rudolph Atcon para elaborar uma proposta para a reestruturação da educação superior. Suas sugestões evidenciam a necessidade de: I) reorganizar a estrutura da educação superior; II) destaque nos princípios de eficiência e produtividade; III) reformular o regime de trabalho docente e a criação de centro de estudos básicos; e IV) criar, ainda, um conselho de reitores das universidades brasileiras ${ }^{9}$. As propostas elaboradas por Atcon foram formuladas tendo como base os princípios postulados pelo governo ditatorial no documento intitulado "Rumo à Reformulação Estrutural da Universidade Brasileira". Segundo este consultor:

[...] a Universidade deveria libertar-se das malhas do "Poder Executivo do Estado". Em seguida defendia uma autonomia que implicasse a completa desvinculação da universidade dos controles administrativos e financeiros do Estado. Como modelo administrativo, um sistema "tipo empresa privada e não de serviço público. [...] Porque é um fato inescapável de que a universidade

9 Seguindo a orientação de Atcon, em 1966 foi fundado o Conselho de Reitores das Universidades Brasileiras (CRUB). Além de idealizador/fundador também trabalhou como o primeiro Secretário-Geral deste conselho. 
autônoma é uma grande empresa e não uma repartição pública. (ATCON, 1966, p. 87. Grifos das autoras)

Dentro desse contexto de reestruturação, o modelo de modernização universitária preconizada previa uma redefinição das funções da universidade em que a formação profissional e a ciência são colocadas exclusivamente a serviço das demandas do desenvolvimentismo. Desta forma, a crítica a esse modelo não tardaria. O suposto consenso será questionado, sendo as questões educacionais traduzidas em custos e benefícios, uma vez que se limita a:

[...] instrumento de aceleração do desenvolvimento, Universidade a serviço de produção prioritária, criação de condições racionais para administração da Universidade. Universidade funcionando como uma empresa privada - com o máximo de rendimento e o mínimo investimento. [...] as questões educacionais foram traduzidas em termos de custos e benefícios. E houve uma grande disseminação desse modo de pensar. (CARDOSO, 1989, p. L7)

A grande maioria das sugestões foi acatada pelo Governo Militar que procurou associar as orientações do USAID com seu projeto de desenvolvimento e segurança nacional. Assim, ao tempo que racionalizava os investimentos a serem aplicados neste nível de formação, também procurou investir numa política de Ciência e Tecnologia vinculada à concepção e projeto nacional desenvolvimentista.

As estratégias desenvolvidas para que a reforma na educação fosse operada dentro dos interesses traçados pelo governo militar revelam a interferência deste nos assuntos relacionados ao campo educacional. Sem meandros, o regime militar desvelava os seus propósitos, ou seja, revelava o caráter antidemocrático de sua proposta ideológica de governo.

No ano seguinte à aprovação da Lei da Reforma Universitária, foi promulgado o Decreto-Lei $\mathrm{n}^{\circ}$. 477, outorgado em 26 de fevereiro de 1969, com base no $\S 1^{\circ}$ do Ato Institucional $\mathrm{n}^{\mathrm{o}} 5$ (AI-5). Por meio desses dispositivos, tornava-se possível, legalmente, a interferência do governo nas questões pertinentes à comunidade acadêmica. Essas legislações garantiam ao governo imputar ações punitivas aos professores, funcionários e alunos quando assim julgasse necessário ${ }^{10}$.

De posse dos mais diversos meios e instrumentos de repressão, o Governo brasileiro legitimava a perseguição política, a censura, o exílio, a imposição de diretrizes políticas e

10 Situações de ingerência do governo e de seus órgãos repressores podem ser também encontrados no Livro Negro da USP, da ADUSP, publicado em 1979 e republicado com o título O controle ideológico na USP (2004) descortinando o cenário cotidiano de repressão, tortura, perseguições, inquéritos e cassações realizadas no período. 
sociais à revelia do que a sociedade civil, na fase pré-golpe, houvera discutido e sinalizado como prioritário.

As medidas almejadas pela Reforma Universitária, conforme planejado, influenciaram diretamente no quantitativo de matrículas realizadas nos anos subsequentes. Embora a Lei 5.540/68 instituísse a formação em nível superior em estabelecimentos universitários associando ensino à pesquisa -, considerava ainda a possibilidade de, excepcionalmente, funcionarem instituições que não adotassem os padrões desse novo modelo, atendendo aos setores que já viam a educação como um mercado a ser expandido e explorado. Assim, a repressão política convive com a expansão mercantil da educação superior, respondendo à necessidade de atender à crescente demanda e aos interesses do capital. Inicialmente, a expansão operava em dois sentidos: na ampliação controlada do setor público federal e pelo crescimento desregrado do setor privado, quase exclusivamente pela organização de estabelecimentos isolados. Paralelamente, verificou-se também a iniciativa de vários estados brasileiros em organizarem faculdades isoladas sob sua responsabilidade jurídico e financeira ${ }^{11}$. Inicialmente, os cursos estavam mais voltados para a área de formação de professores a fim de atender a demanda do $1^{\circ}$ e $2^{\circ}$ Graus ${ }^{12}$, e devido ao baixo custo para sua instalação.

Decorrente desta política, é registrada nas décadas subsequentes a ampliação percentual das matrículas no ensino superior, a maior parte em instituições particulares, uma amostra do que viria a ser considerada a expansão mercantil da educação superior brasileira. Estas, amparadas na excepcionalidade prevista e regulamentada desde a Lei 5.540/68, também encontraram suporte nos critérios estabelecidos a partir da promulgação da Constituição Federal de 1988 que instituiu a diversificação dos estabelecimentos de educação superior.

\section{Marcas da Heteronomia na Universidade a partir da reconfiguração do Estado brasileiro}

Conforme apontado anteriormente, a década de 1970 ficou registrada na memória da sociedade brasileira como um dos períodos de maior recrudescimento político já registrado na

11 A partir deste período, a história da educação superior passou a conviver com a diversificação da tipologia de instituições de nível superior que vão perdendo a referência do modelo universitário e passa a coexistir com as Faculdades, Institutos, Escolas Superiores, descaracterizando o modelo de universidade preconizado pela reforma de 1968.

12 Denominação dada pela Lei 5.692/71 às etapas do Ensino Fundamental e Ensino Médio, respectivamente, e que vigorou até 1996. 
história do país, marcado pela perseguição aos partidos/organizações de oposição ao regime instituído, bem como pela imposição do silêncio a qualquer indício de insatisfação. Os movimentos sociais - estudantil, sindical, trabalhadores rurais -, fortalecidos pela disputa e pelos embates políticos realizados no início dos anos de 1960, foram amordaçados pelo governo ditatorial.

O controle político-ideológico começa a dar indícios das suas contradições e fragilidades, especialmente ao final dos anos de 1970, em função do caos plantado na economia, pós-euforia do milagre econômico e em, também, função do processo de asfixia crônica que a sociedade civil havia sido submetida nos anos anteriores, apresentando, portanto, necessidade imediata de oxigenação. A crise econômica revelava a fragilidade do projeto político da social democracia. Para Silva Júnior,

\begin{abstract}
A contradição, entre, de um lado, um profundo deficit social e produtivo, e, de outro, a redemocratização do poder, produziu a referida politização da crise econômica. Esse movimento enfraqueceu os movimentos sociais e as instituições e organizações políticas de mediação entre o Estado e a sociedade civil, possibilitando o ajuste socioeconômico e político do início dos anos noventa necessário para superação da crise capitalista assentada nas propostas social-democratas predominantes no século XX, que se fizeram presentes no Chile e em alguns países da Europa, nos Estados Unidos e na América Latina. (SILVA JUNIOR, 2004, p. 5)
\end{abstract}

Não desconsiderando a importância dos movimentos sociais e políticos organizados para que o processo de reabertura política se instaurasse, reconhece-se que este foi "lento e gradual". Não por incapacidade de organização e mobilização da sociedade civil, mas sim em função do aparato de controle, censura e tortura existente. Afinal, os que historicamente estavam à frente do poder não iriam permitir qualquer flexibilização que colocasse em jogo seus interesses de grupo político-econômico.

Disposta a debater os rumos que a Assembleia Constituinte traçaria para elaborar a nova Carta Constitucional, a sociedade civil procurou mobilizar-se em diversos segmentos. Educadores, estudantes e demais representações da sociedade articulam-se em setores organizados - Conselho de Reitores das Universidades Brasileiras - CRUB; Conferência Nacional dos Bispos Brasileiros - CNBB; a Ordem dos Advogados do Brasil - OAB; representantes das Comunidades de Base; e várias outras organizações, entre elas federações sindicais, partidos de esquerda, facções radicais dos partidos que se oponham a manutenção do status quo. As discussões realizadas no período da Assembleia Constituinte revelavam a 
arquitetura traçada, tendo em vista o projeto de Estado idealizado pelos representantes dos capitais nacional e internacional no país, a saber, a elite política-econômica.

$\mathrm{Na}$ área educacional, as perspectivas não eram as melhores. Restringindo a análise à educação superior, percebe-se o empenho dos representantes dos estabelecimentos privados em assegurar constitucionalmente a menor participação possível do Estado neste nível de formação, a partir, principalmente, do estabelecimento das metas de flexibilização/desregulamentação. Peixoto (1998) chama a atenção para os debates realizados acerca do financiamento da educação superior, destacando a participação do Conselho de Secretários de Educação, da União Nacional dos Dirigentes Municipais de Educação e do Fórum Nacional de Educação na Constituinte em Defesa do Ensino Público e Gratuito, que atuaram vedando a transferência de recursos públicos a estabelecimentos que não integrassem os estabelecimentos oficiais de ensino.

A Comissão de Educação da Assembleia foi arena da disputa entre representantes das instituições particulares e públicas; entre intelectuais e congressistas. Uns defendiam a inclusão da autonomia universitária no texto constitucional, enquanto outros eram contra a sua inclusão por defenderem que não é papel de uma Constituição este tipo de normatização. Após incansáveis debates entre grupos que defendiam interesses tão antagônicos, a autonomia universitária plena foi expressa na Constituição Federal. Segundo o Artigo 207 da Constituição de 1988, "as universidades gozam de autonomia didático-científica, administrativa e de gestão financeira e patrimonial, e obedecerão ao princípio de indissociabilidade entre ensino, pesquisa e extensão”. Fávero (1999) apresenta os seguintes aspectos previstos nesta perspectiva de autonomia universitária: a autonomia didático-científica implica liberdade da universidade para: a) estabelecer seus objetivos, organizando o ensino, a pesquisa e a extensão sem quaisquer restrições doutrinárias ou políticas de graduação e pós-graduação e outros a serem realizados sob sua responsabilidade; b) definir linhas de pesquisa; c) criar, organizar, modificar e extinguir cursos; d) elaborar o calendário escolar e o regime de trabalho didático; e) fixar critérios e normas de seleção, admissão, promoção e transferência de alunos; e f) outorgar graus, diplomas, certificados e outros títulos acadêmicos. Na mesma linha, do ponto de vista administrativo, as universidades têm plena liberdade de: a) organizar-se internamente estabelecendo suas instâncias decisórias, na forma que lhes aprouver; b) elaborar e reformular seus estatutos e regimentos; e c) estabelecer seu quadro de pessoal docente e técnico-administrativo, de acordo com seu planejamento didático-científico. A terceira dimensão refere-se à autonomia de gestões financeira e patrimonial para: a) outorgar competência à universidade para elaborar seu 
orçamento e executar suas despesas, a partir de suas unidades básicas, submetendo-as à aprovação dos colegiados superiores; b) receber os recursos que o Poder Público é obrigado a repassar-lhe para o pagamento de pessoal, despesas de capital e outros custeios; c) administrar os rendimentos próprios de seu patrimônio e deles disporem, na forma de seu estatuto; d) receber heranças, legados e cooperação financeira resultante de convênios com entidades públicas e privada; e e) realizar contratos referentes a obras, compras, alienação ou concessão, de acordo com os procedimentos administrativos de licitação.

A julgar pela constitucionalidade que a autonomia logrou com a promulgação da Constituição Federal de 1988, é possível fazer o exercício quanto ao seu significado pétreo (ou pátrio). Fato é que, segundo Souza (2001):

A capacidade de autogestão institucional, que passa pela administração, pelas finanças e pelo patrimônio, alcança seu mais alto significado na autonomia didático-cientifica, ou seja, acadêmica. Pois, não raro, [...] essa autonomia tem sido solenemente ignorada, para que se implantem medidas exógenas nascidas dos laboratórios normativos do sistema, e que se tornam impositivas no dia-adia do funcionamento das universidades. (SOUZA, 2001, p. 98-99)

No entanto, a disputa não se esgota nesse momento, uma vez que as articulações acerca da elaboração da Lei de Diretrizes e Bases da Educação Brasileira já estavam na pauta do dia. Segundo Silva Júnior (2004), alimentadas pelas alterações oriundas do campo políticoeconômico sob especial inspiração das reformas neoliberais regidas pela então primeira ministra da Inglaterra Margareth Tatcher e pelo então presidente dos Estados Unidos da América Donald Reagan , o final dos anos de 1980 e início dos anos 1990 preconizavam, principalmente, a diminuição do papel do Estado, desregulamentação da economia, combate ao sindicalismo, privatizações e redução dos gastos públicos provocando o que Silva Junior irá descrever como:

[...] radicais transformações nas formas de produção da vida humana em todas as suas dimensões, em razão da própria racionalidade da formação econômico-social capitalista. A base produtiva altera-se de forma significativa por meio do desenvolvimento científico, a economia em sua dimensão micro reestrutura-se em face de seu próprio movimento e do ocorrido com a mundialização no âmbito macro, transformando de forma radical as relações entre as grandes corporações, bem como o seu paradigma organizacional e de gestão. No âmbito político, a esfera pública restringe-se e desregulamenta-se, num primeiro momento, para regulamentar-se novamente, em seguida, e assim possibilitar a expansão da esfera privada, num movimento com origem no Estado, mediante reformas estruturais orientadas por teorias gerenciais próprias do mundo dos negócios, em vez de por teorias políticas relacionadas à cidadania, ainda que calcadas na concepção liberal. (SILVA JUNIOR, 2004, p. 6) 
Neste contexto, foram gestadas modificações direcionadas tanto à mudança organizacional quanto as relacionadas à concepção de educação superior que, na grande maioria das vezes, estava associada à nova configuração mundial. Segundo Sguissardi (2000, p. 243), organismos multilaterais propagaram três teses fundamentais relacionadas à educação superior: 1) o ensino superior seria antes um bem privado que público; 2) os retornos individual e social dos investimentos em educação superior seria inferior ao dos investimentos aplicados na educação básica; e 3) a universidade de pesquisa - da associação ensino, pesquisa e extensão seria muito cara, tanto para os países ricos, quanto especialmente para os países pobres, ou em desenvolvimento, às voltas com problemas de crônico deficit público.

Considerando a velocidade das transformações que esse modelo de desenvolvimento configurou para o estabelecimento de uma nova ordem mundial, verificou-se no Brasil as sintonias política e harmoniosa entre o que pressupunha o grupo à frente da Reforma do Estado, especialmente no octênio de Fernando Henrique Cardoso (1995-2002), e os pressupostos então orientadores da concepção de Estado formulados por organismos internacionais. A área educacional foi atingida em todos os níveis e modalidades de ensino num curto espaço de tempo. Segundo o Fórum Nacional em Defesa da Escola Pública - FNDEP:

O referido consenso obtido pelo governo FHC não pode ser analisado a partir de uma perspectiva endógena, como se fosse resultante da vontade pessoal do Presidente ou da obstinação do Senador Darcy Ribeiro. O exame mais cuidadoso do processo e construção da política educacional do governo aponta como matriz conceitual as diretrizes do Banco Mundial, comum aos vários países latino-americanos. Desta forma, é preciso analisar a vitória do projeto governamental como sendo a vitória de uma determinada concepção de Estado e de sociedade, que pode ser denominada neoliberal. (FNDEP, 1997, p. 165)

A constatação pura e simples deste processo erradica a possibilidade de análise de como se deu a construção da Lei. Utilizando os mais diversos expedientes, tanto legais quanto burocráticos, o governo foi, aos poucos, construindo o cenário que a educação nacional neste contexto deveria possuir. Segundo o FNDEP:

A estratégia governamental obteve êxito ao evitar confrontes de "projetos". Assim, o governo FHC valeu-se de uma miríade de projetos de lei, medidas provisórias, PEC's. Decretos-Lei e pouco a pouco, foi configurando a sua política educacional. A LDB aprovada tem como função conformar essas diversas normalizações em seu arcabouço jurídico único, que, diga-se de passagem, constitui uma "nova colcha de retalhos". Os exemplos dessa estratégia são inúmeros: Lei no 9.192/95- escolha dos dirigentes universitários, ferindo a autonomia das universidades: Emenda Constitucional $n^{\circ} 14-$ Fundo 
de Manutenção e Desenvolvimento do Ensino Fundamental e de valorização do Magistério, normalizado pela Lei 9424/96, [...]. (FNDEP, 1997, p. 167)

As políticas endereçadas à educação superior também revelavam, na sua concepção, a congruência com o projeto neoliberal consubstanciada na Reforma do Estado brasileiro que as classes dominantes, servindo-se dos mais diversos mecanismos para reforçar seus interesses, procuraram deslegitimar o modelo de Estado em vigência e assim, viabilizar as "reformas" consideradas "necessárias". Desregulamentar os padrões econômicos, políticos e ideológicas existentes e legitimar/naturalizar uma nova perspectiva de acumulação de capital em construção tornaram-se a meta.

As diretrizes então estabelecidas para a educação superior articulavam-se às políticas apresentadas no contexto da Reforma do Estado uma vez que, concordando com Chauí (1999), modernizar neoliberalmente a universidade significa destruir o mais moderno dos valores conquistados pelas ciências e humanidades: o trabalho autônomo e a autonomia criadora. Podendo implicar na destruição de uma das conquistas democráticas mais importantes da modernidade: a dimensão pública da pesquisa, tanto na sua realização quanto em sua destinação.

Essa política materializa-se no cotidiano universitário ao exercer forte influência nas suas atividades-fins, caracterizando, assim, uma política que favorece a banalização da função principal a ser desenvolvida pelas universidades - a indissociabilidade entre o ensino, a pesquisa e a extensão. Este projeto fragmenta esta perspectiva conforme previsto na Constituição Federal de 1988, uma vez que passa a ser considerado por muitos dirigentes como oneroso e ineficiente. Neves e Fernandes (2002, p. 26) asseveram que:

A preponderância da indissociabilidade entre ensino, pesquisa e extensão como princípio educativo da educação superior brasileira nos anos de desenvolvimentismo perde a sua funcionalidade nos dias atuais, já que a política neoliberal prescinde da produção do conhecimento científico e tecnológico em âmbito nacional.

Segundo De Paula (2006), a partir da década de 1990, com a política de contensão de investimentos na educação superior pública, o Governo contribui decisoriamente na aceleração do desmonte desta instituição e com a expansão do processo de privatização do sistema de ensino superior, inserindo-o na lógica do capital. O conceito clássico de autonomia, segundo o autor, passa a ser crescentemente associado à autonomia financeira, isto é, à capacidade de captar recursos junto ao mercado e ao setor privado. Enquanto isso, o Estado se retira enquanto 
provedor, mas mantém o controle por meio de sistemas de regulação e avaliação externa. Em 20 de dezembro de 1996, foi aprovada no Senado Federal a Lei nº 9.394 que fixou as Diretrizes e Bases da Educação Nacional. A análise do texto legal revela tanto a integração quanto as disputas entre os principais personagens e grupos envolvidos nesta contenda.

O Capítulo IV, "Da Educação Superior”, explicita a concepção de educação superior que se pretendia defender e implementar a partir daquele momento. A concepção de autonomia expressa na referida Lei, a exemplo do Art. 53, está diretamente vinculada a indicadores de eficiência que, além de não serem previamente explicitados, não possuem qualquer consenso a este respeito.

Neste artigo, os legisladores, tentando condensar as discussões realizadas nos fóruns específicos, determinaram como atribuições das universidades brasileiras: criar, organizar e extinguir cursos e programas de educação superior; fixar os currículos dos seus cursos e programas; estabelecer planos, programas e projetos de pesquisa científica, produção artística e atividades de extensão; fixar o número de vagas; elaborar e reformar os seus estatutos e regimentos; conferir graus, diplomas e outros títulos; firmar contratos, acordos e convênios; aprovar e executar planos, programas e projetos de investimentos referentes a obras, serviços e aquisições em geral, bem como administrar rendimentos conforme dispositivos institucionais; administrar os rendimentos; receber subvenções, doações, heranças, legados e cooperação financeira resultante de convênios com entidades públicas e privadas. A fim de garantir sua autonomia didático-científica, caberá aos colegiados de ensino e pesquisa da universidades decidirem sobre os quatro primeiros aspectos acima relacionados e também sobre a contratação e dispensa de professores e os planos de carreira docente.

A concepção de autonomia universitária explicitada na Lei revela que a autonomia "concedida" às universidades brasileiras, quando não cumpre os aspectos burocráticos, revela a limitação das suas ações em relação às orientações de caráter legal ou orçamentário. Esse último formulado para além do espaço da universidade.

No contexto de construção e promulgação da LDB é possível identificar estreita sintonia entre as diretrizes defendidas pelo Ministério da Administração e da Reforma do Estado (MARE) para a educação superior brasileira tendo em vista uma suposta equidade, eficiência e qualidade nos "serviços" a serem prestados para a sociedade. Neste esteio recomendações do Banco Mundial sugeriam: 1) Promoção de maior diferenciação das instituições, incluindo o estabelecimento de instituições privadas; 2) PAmpliação de incentivos para que as instituições públicas diversifiquem as fontes de financiamento; 3) Redefinição da função do governo no 
ensino superior e 4) Seguir políticas que estejam destinadas a outorgar prioridade aos objetivos da qualidade e equidade" (BANCO MUNDIAL, 1995, p. 4).

Essas orientações sintetizam a pertinência do ajuste econômico e fiscal necessários para assegurar, segundo o governo, o desenvolvimento econômico. Foi imposto a educação superior brasileira o risco de, em pouco tempo, perder o perfil universitário, limitando-se a se tornar instituições de natureza diversificada, porém mais adequadas "às necessidades do mercado de trabalho" (BANCO MUNDIAL, 1995, p. 31). Nessa perspectiva, e tendo em vista a necessidade de manterem "produtivas", as universidades foram obrigadas a buscar outras fontes de financiamento e o preço a ser pago foi a perda da sua identidade, ainda que gradativa e silenciosamente. Segundo Chauí (2001),

A autonomia passou a significar uma capacidade operacional de gestão de recursos públicos e privados, e não mais o modo de inserção da instituição universitária num sistema nacional de educação e pesquisa nem sua forma de relação com a sociedade e o Estado. (CHAUÍ, 2001, p. 204-5)

A diversificação e a heteronomia passaram a ser partes constitutivas da realidade da educação superior brasileira. Com a redução orçamentária, as universidades são "orientadas" a trabalhar numa perspectiva produtivista, em uma "crescente desfuncionalização para outros fins, assoladas pela panaceia do eficientismo e dos artifícios da administração gerencial, que não são mais do que formas de produzir sua subserviência ao capital”, segundo Minto (2014. p. 284). Neste contexto, é verificado a submissão aos critérios e determinações exigidos pelos editais externos de financiamento das atividades fins, caracterizando a heteronomia institucional.

Outro problema identificado é o fato da educação superior limitar a sua oferta à formação de profissionais que o mercado determina como prioritária, contribuindo para o direcionamento da oferta para poucos cursos, normalmente os que demandam maior apelo popular e menores investimentos financeiros em laboratórios e instalações físicas, provocando um forte desequilíbrio no panorama das "vocações” profissionais dos jovens brasileiros.

Este cenário também se fez presente nos governos da era petista. Estes imprimiram como uma de suas marcas a expansão mercantil massificada, tanto na modalidade presencial quanto na modalidade à distância, viabilizada pelas inúmeras concessões legais que favoreceram a grupos privatistas se tornarem verdadeiros conglomerados educacionais com estreita vinculação com o capital internacional, que insiste em multiplicar a oferta de cursos de 
formação aligeirada e rasa, sem qualquer aproximação com o sentido etimológico que o constitui.

As questões apresentadas acerca da autonomia nas instituições de educação superior no Brasil, especialmente as instituições públicas universitárias, apresentam, em diversos momentos, contradições característica da luta entre interesses antagônicos. Os interesses expressos pelas classes dominantes, na grande maioria das vezes, conseguiram frear, anular, orientar, determinar o significado deste princípio no interior das IES. Embora não se possa perder a dimensão das conquistas que a comunidade universitária e a sociedade civil, fazendo resistência a governos declaradamente de "direita" ou de "esquerda", lograram ao longo dos embates estabelecidos contra os interesses do capital, estes, na maioria das vezes, conseguiram imprimir a sua marca e assim, definir o que era razoável para sua efetivação.

\section{Considerações Finais}

Após a era dos governos petistas, encerrada abruptamente em 2016 em função de um golpe parlamentar e midiático, temos o aprofundamento dos ataques à educação superior pública e gratuita também no Governo Temer, agora intensificado irresponsavelmente no Governo Bolsonaro.

O Projeto Future-se, submetido à Consulta Popular em julho de 2019, apresenta, na sua essência, os princípios organizativos e de concepção de educação superior então formulados na década de 1990, os quais, na época, em função da mobilização popular, não havia logrado êxito. $\mathrm{Na}$ atual versão, esse projeto está estruturado em três eixos: Gestão, Governança e Empreendedorismo; Pesquisa e Inovação; e Internacionalização. Segundo o site do MEC, as principais vantagens do programa são: aumento das receitas por meio de fomento à captação de recursos próprios e com maior segurança jurídica; maior flexibilidade para realizar despesas (que as tornarão menos dependentes do orçamento, contingenciamento e PEC do gasto) e que serão administradas por uma Organização Social-OS.

Atualmente, a relação de vinculação das universidades e dos institutos federais de educação às Organizações Sociais torna-se condição sine qua non para sua existência, embora haja resistência a esse modelo por meio da recusa recorrente na grande maioria de estabelecimentos, via documentos expressos por seus respectivos Conselhos Superiores.

O Future-se é mais um projeto elaborado pelo "alto", sem qualquer participação da comunidade acadêmica, sem qualquer contribuição de pesquisadores e que revela sua intenção 
privatista de um dos maiores patrimônios da sociedade brasileira, o seu sistema federal de ensino que compreende as Universidades, os Institutos e os Centros Tecnológicos. Elaborado por profissionais com estreita vinculação com a área financeira, esse projeto propõe o aniquilamento da graduação, da pós-graduação, da pesquisa e da extensão no Brasil. Interesses e racionalidade econômica se sobrepõem as funções da educação superior de promover uma ciência independente e autônoma e formar sujeitos para o mundo do trabalho e não para o mercado de trabalho.

Sem ciência e inovação não há futuro e nem soberania. Absolutamente todos os Estados considerados fortes e desenvolvidos investiram, e continuam investindo, no desenvolvimento da pesquisa com recursos públicos. Faz-se urgente discutir qual o projeto de educação o Estado Brasileiro, submetido ao capital aliado à lógica mercantilista, projeta para a classe trabalhadora deste país. Este cenário ratifica a análise de Freire (1984, p. 89), ao afirmar que "Seria uma atitude ingênua esperar que as classes dominantes desenvolvessem uma forma de educação que proporcionasse às classes dominadas perceber as injustiças sociais de maneira crítica”.

É preciso fortalecer as trincheiras da democracia, em que a luta e a resistência são forjadas no fogo da superação, da consciência de classe. Na esperança de um mundo mais humanitário, a autonomia, compreendida como o oposto dialético da alienação, torna-se, portanto, um princípio pétreo, fundamental, um rompimento com a lógica do capital, a qual sendo incorrigível, jamais admitirá alterações em seus fundamentos profundamente enraizados. Armar-se de utopia e ter como horizonte de lutas a transformação do atual contexto do ensino superior brasileiro, pois, como afirmam Marx e Engels (1977, p. 119), "a coincidência da modificação das circunstâncias e da atividade humana só pode ser apreendida como prática transformadora".

\section{REFERÊNCIAS}

ATCON, Rudolph P. Rumo à reformulação estrutural da universidade brasileira. Rio de Janeiro, MEC/DESU. 1966.

BANCO MUNDIAL. La enseñanza superior: las lecciones derivadas de la experiencia. Banco Mundial (El Desarrolloenlapráctica). Washington, D.C: BIRD/BANCO MUNDIAL, Washington, 1995.

CARDOSO, Irene. A avaliação acadêmica e as fundações. Cadernos ANDES, n.7, p.7-35, fev. 1989

CHAUÍ, Marilena. Escritos sobre a universidade. São Paulo: Editora UNESP, 2001. 
CUNHA, Luís Antônio. A universidade crítica: o ensino superior na república populista. Rio de Janeiro: Francisco Alves, 1983. http://www.cedes.unicamp.br/

FÁVERO, Maria de Lourdes de A. Da Cátedra Universitária ao Departamento: subsídios para discussão. Anais. 23 ${ }^{\mathrm{a}}$ Reunião da ANPEd, 2000. Disponível em:

<http://www.anped.org.br/reunioes/23/textos/1118t.PDF>. Acesso em março de 2020.

FERNANDES, Florestan. A revolução burguesa: ensaio de interpretação sociológica. Rio de Janeiro. Zahar, 1975a.

FERNANDES, Florestan. Universidade brasileira: reforma ou Revolução. São Paulo. AlfaOmega, 1979 b.

FNDEP. A nova LDB na Avaliação do Fórum em Defesa da Escola Pública. Universidade e Sociedade. Ano VII, Nº 13, Julho. 1997.

FREIRE, Paulo. Ação cultural para a liberdade. Rio de Janeiro: Paz e Terra, 1984. http://www.aduff.org.br/manchetes/20080908_manobras.htm

MARX, Karl; ENGELS Friedrich. Teses sobre Freuerbach. São Paulo: ômega, 1977.

MINTO, Lalo Watanabe. A Educação da "Miséria": particularidade capitalista e educação superior no Brasil. São Paulo: Outras Expressões, 2014.

NEVES, Lúcia Maria Wanderley; FERNANDES, Romildo Rapouso. Política neoliberal e educação superior. In: NEVES, Lúcia Maria Wanderley (org.). O empresariamento da educação: novos contornos do ensino superior no Brasil dos anos 1990. São Paulo: Xamã, 2002.

http://www.interface.org.br/revista4/ensaio4.pdfhttp://www.anped.org.br/27/gt11/t113.pdf

DE PAULA, Maria de Fátima. A perda da identidade e da autonomia da universidade brasileira no contexto do neoliberalismo. Revista Eletrônica do Grupo Aleph - Faculdade de Educação - UFF. Ano II - Número 09 - Fevereiro/Março de 2006 - ISSN 1807-6211. Disponível em

$\langle$ http://www.uff.br/aleph/textos_em_pdf/a_perda_da_identidade_da_universidade.pdf $>$. Acesso em dezembro de 2007.

PEIXOTO, Maria do Carmo de Lacerda. Relações de poder na universidade pública brasileira. Revista Brasileira de Estudos Pedagógicos, Brasília, v. 78, n.188, 1998.

PINTO, Álvaro Vieira. A questão da universidade. São Paulo: Cortez: Autores Associados, 1986.

SGUISSARDI, Valdemar (Org.). Educação superior: velhos e novos desafios. São Paulo: Xamã, 2000, p. 179-196. 
SGUISSARDI, Valdemar. Universidade no Brasil: dos modelos clássicos aos modelos de ocasião? In: MOROSINI, M. (Org). A universidade no Brasil: concepções e modelos. Brasília, DF: Inep, 2006.

SILVA JÚNIOR, João dos Reis. OLIVEIRA, João Ferreira de. MANCEBO, Deise (Org.). Reforma Universitária: dimensões e perspectivas. SP: Editora Alínea, 2006. (Coleções universitárias).

SILVA JÚNIOR, João dos Reis. Prefácio: Educação, Trabalho e Formação do Cidadão Brasileiro na História Recente do Brasil. In: KOBER, Claudia Mattos. Qualificação profissional uma tarefa de Sísifo. Campinas: Autores Associados, 2004.

SINGER, Helena. Quando o "diálogo" é a violência. Educ. Soc. [online].2001, vol. 22, no. 77. Disponível em < http://www.scielo.br/scielo.php?pid=S0101-

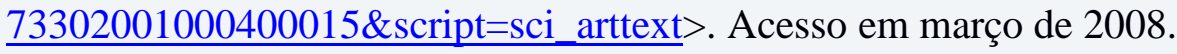

SOUZA, Paulo Nathanael Pereira. LDB e Educação Superior: estrutura e funcionamento. $2^{\mathrm{a}}$ ed. revisada e ampliada. São Paulo: Pioneira Thomson Learning, 2001.

\section{SOBRE AS AUTORAS:}

\section{Iracema Oliveira Lima}

Doutora em Educação pela Universidade Federal de São Carlos (UFSCar); Docente da Universidade Estadual do Sudoeste da Bahia - Brasil; Docente do Programa de Pós-Graduação em Educação; Coordena o Grupo de Pesquisa em Políticas para a Educação Superior- GEPPES. E-mail: iracema.lima@uesb.edu.br

iD http://orcid.org/0000-0002-6761-3704

\section{Leila Pio Mororó}

Doutorado em Educação pela Universidade Federal de São Carlos (UFSCar); Docente da Universidade Estadual do Sudoeste da Bahia - Brasil; Docente do Programa de Pós-Graduação em Educação; Coordena o Grupo de Pesquisa Núcleo de Estudo, Pesquisa e Formação de Professores - NEFOP. E-mail: leila.mororo@uesb.edu.br

(iD https://orcid.org/0000-0001-90745257 